\title{
Falls in Elderly Patients with Stroke
}

\author{
Walid Kamal Abdelbasset, $\mathrm{PhD}^{1,2^{*}}$ \\ ${ }^{I}$ Department of Health and Rehabilitation Sciences, College of Applied Medical Sciences, \\ Prince Sattam bin Abdulaziz University, Al-Kharj, Saudi Arabia \\ ${ }^{2}$ Department of Physical Therapy, Kasr Al-Aini Hospital, Cairo University, Giza, Egypt
}

\begin{abstract}
The present review aims to identify the prevalence of falls, to describe the factors related to falls among elderly stroke patients, and to demonstrate the desired interventions to prevent falling among those patients. This review was conducted using PubMed, SCOPUS, Web of Science, and Medline to determine the incidence, risk factors, and favorable procedures to prevent and manage falls among elderly stroke patients. Falls lead to injuries, fractures, and impairments of the quality of life. Elderly stroke patients are more susceptible to falling than their healthy peers, which may result in greater restrictions on activity and mobility. Previous studies have documented the incredible prevalence of falls among the elderly who have suffered a stroke. Our study led to the conclusion that falls should be assessed to determine how to prevent and control them among elderly stroke patients. Physical therapy and rehabilitation modalities have a key role to play in improving the health status and prevent falling among those patients. (International Journal of Biomedicine. 2020;10(4):330-333.)
\end{abstract}

Key Words: stroke $\bullet$ falls $\bullet$ elderly $\bullet$ rehabilitation

S troke is documented as the second commonest cause of death worldwide, after cardiac diseases, and they cause a high rate of disability, mortality, and morbidity worldwide. ${ }^{(1,2)}$ Despite the worldwide decrease in the mortality rate in the last decade, the number of elderly people with stroke and fatal stroke increases each year, more in Asia than in America or Europe. ${ }^{(3)}$

Stroke commonly occurs among elderly populations, afflicting nearly $9 \%$ of the elderly between 65 and 79 years and around $15 \%$ of those older than 80 years. ${ }^{(4)}$ By 2030, the number of stroke survivors among elderly populations may increase to approximately 10 million. ${ }^{(4,5)}$

Falls among stroke patients

Falls are considered as the most common health issue following a stroke, leading to high rates of mortality and morbidity. ${ }^{(6)}$ The falling rate among stroke patients has ranged between $25 \%$ and $44 \%$, particularly among those who are experiencing locomotor dysfunction. ${ }^{(7,8)}$ Falling is a common complication among the aged population, increasing disability and dependence. ${ }^{(9)}$ Approximately, $90 \%$ of the injuries among the

*Corresponding author: Walid Kamal Abdelbasset, PhD. Department of Health and Rehabilitation Sciences, College of Applied Medical Sciences, Prince Sattam bin Abdulaziz University, Al-Kharj, Saudi Arabia.E-mail: walidkamal.wr@gmail.com elderly result from falling ${ }^{(10)}$ leading to a high economic burden for healthcare. Fractures commonly occur as a consequence of falls among the elderly, specifically hip fractures, which cause a potential disability and disturbance of health overall. In elderly stroke survivors, the risk of hip fracture is 4 times higher than among their peers in the general population. ${ }^{(10,11)}$

Characteristics of falling among elderly stroke patients

The falling features and circumstances for elderly and non-stroke patients have been assessed in early studies. ${ }^{(12,13)}$ Nevertheless, studies that assess falling in post-stroke patients are limited. One previous study found that $50 \%$ of their studied sample of post-stroke patients had a history of falling related to disturbed balance and insufficient attention. ${ }^{(14)}$ Another study reported that chronic stroke patients who suffered from falling had disturbed mobility and inability to perform their daily activities, with higher levels of depression and anxiety than stroke patients with no falling history. ${ }^{(15)}$ However, it was documented that post-stroke patients commonly fall, ${ }^{(16)}$ and risk factors of falling are numerous among stroke survivors. ${ }^{(14,15)}$ Some studies have reported that the incidence of falling among older adult patients reaches $76 \%,{ }^{(17,18)}$ and other studies have reported that the incidence of falling among stroke patients is approximately $30 \% .^{(16,19)}$ Other studies have reported that falling after a stroke results in injuries and that $20 \%$ of these injuries require a medical attention. ${ }^{(12,20)}$ 
Despite a prior study that found similar characteristics among falling and non-falling stroke survivors in motor control and mobility, falling patients showed higher disabilities and comorbidities, ${ }^{(15)}$ indicating that stroke associated with disabilities commonly contribute to falling. Also, another study concluded that stroke patients with orthostatic hypotension are commonly susceptible to falling.(21) Regarding the circumstances of falling, there is clearly a strong association between disability and falling risk. It is expected that falling can commonly take place in association with daily home activities, such as feeding, washing, showering, and toileting. In addition to falling related to daily home activities, patients commonly fall because of slips or trips. Geriatric literature has reported a high prevalence of slips and trips on such small obstructions as sidewalk cracks, carpets, curbs, cords, and roots of trees. ${ }^{(12,22)}$ Also, stroke survivors may slip or trip on ice or wet surfaces because of diminished vision or other sensory abilities.

Falling history has documented that falls are likely associated with physical and mental impairments, including carelessness in some home details, such as alcohol drinking, poor quality of sleep, tying shoes, and the use of assistive devices. Therefore, the prevention of falling after a stroke should not concentrate only on improving range of motion and muscle strengthening but also on modifying associated risk factors of falling.

Risk factors for falling among elderly stroke patients

Generally, independent risk factors for falls among the elderly include muscle weakness, recurrent falling, psychological medications, visual or other sensory deficiency, disturbed gait, walking deficits, physical restrictions, anxiety, dizziness, depression, cognitive dysfunction, orthostatic hypotension, incontinence, diabetes, female gender, receiving poly medications, and being older than 80 years. ${ }^{(23)}$

Recently, a systematic review demonstrated that among the elderly population some risk factors have a strong relationship to falling, such as falling history, disturbed gait, using walking aids, neurological diseases, vertigo, and use of antiepileptic medications. ${ }^{(24)}$ Also, an observational study found that lesions of the white-matter area of the brain are likely a risk factor predictor for falling. ${ }^{(25)}$ Further, it has been documented that the falling risks are directly related to the pain severity of musculoskeletal disorders, the number of affected joints, and amount of interference with daily living activities. ${ }^{(26)}$ Orthostatic hypotension is commonly prevalent among the elderly, leading to gait impairment and falling. ${ }^{(27)}$ Moreover, another study on four elderly subjects documented that obstructive sleep apnea leads to falling-related injuries. ${ }^{(28)}$

Regarding falling among elderly stroke patients, in addition to the previous risk factors, a recent study found a positive correlation between the prevalence of falling and indoor tripping hazards with no differences between stroke patients and non-stroke peers, suggesting that for stroke patients there is a greater risk of falling outdoors than indoors. ${ }^{(29)}$ Stroke patients have a higher susceptibility to falling than matched controls, ${ }^{(30,31)}$ and the risk of falls increases with high physical disabilities. ${ }^{(32)}$ Both indoor and outdoor environments may raise the probability of falls among stroke survivors, specifically those experiencing physical limitations. ${ }^{(33,34)}$ The majority of outdoor predictors for falling are sidewalks and sidewalk obstructions; ${ }^{(35)}$ however, the indoor predictors are associated with tripping risks, such as poor light and loose carpets. ${ }^{(36)}$ Anxiety and fear of falling are additional risk factors observed among those who fall outdoors. ${ }^{(37)}$ Fear of falling may be combined with social factors that prevent the survivor from asking family members or neighbors to assist with walking. ${ }^{(38)}$

Prevention of falling among elderly stroke patients

Previous studies have shown several successful treatment modalities for preventing falls and associated risk factors. ${ }^{(39-41)}$ An effortless and easy modality having a highly beneficial influence is a home assistant to pick up anything that presents a risk of tripping and to clean up clutter and clear walking pathways at home. Generally, treatment modalities for preventing falling among the elderly are classified into particular or multi-section treatment. The particular, evidence-based treatment for preventing falls among the elderly include home evaluation and adjustment for those at high-risk, adherence to exercise training such as gait training, strengthening, balance, and stretching exercises, and receiving more than 700IU of vitamin D supplements per day. ${ }^{(42-44)}$ However, the multi-section treatment shows beneficial effects to prevent falling among the elderly, including reviewing and reducing psychological medications, ${ }^{(42)}$ assessing and treating orthostatic hypotension, ${ }^{(23)}$ rapid cataract surgery for an impacted eye,${ }^{(42)}$ wearing multifocal glasses when outdoors, ${ }^{(45)}$ using anti-slipping shoes outdoors during winter, ${ }^{(46)}$ and cardiac pacing in cardiac inhibitory carotid sinus syndrome. ${ }^{(47)}$ Multi-section treatment is strongly recommended because it assesses individualized risk factors for falling and planning the intervention program for reducing that risk. ${ }^{(42)}$

\section{Acknowledgments}

This publication was supported by the Deanship of Scientific Research at Prince Sattam bin Abdulaziz University.

\section{Competing Interests} interests.

\section{References}

1. Bonita R, Mendis S, Truelsen T, Bogousslavsky J, Toole J, Yatsu F. The global stroke initiative. Lancet Neurol. 2004 Jul;3(7):391-3. doi: 10.1016/S1474-4422(04)00800-2.

2. Feigin VL, Forouzanfar MH, Krishnamurthi R, Mensah GA, Connor M, Bennett DA, Moran AE, Sacco RL, Anderson L, Truelsen T, O'Donnell M, Venketasubramanian N, BarkerCollo S, Lawes CM, Wang W, Shinohara Y, Witt E, Ezzati M, Naghavi M, Murray C; Global Burden of Diseases, Injuries, and Risk Factors Study 2010 (GBD 2010) and the GBD Stroke Experts Group. Global and regional burden of stroke during 1990-2010: findings from the Global Burden of Disease Study 2010. Lancet. 2014 Jan 18;383(9913):245-54. doi: 10.1016/s0140-6736(13)61953-4. Erratum in: Lancet. 2014 Jan 18;383(9913):218. 
3. Kim JS. Stroke in Asia: a global disaster. Int J Stroke. 2014 Oct;9(7):856-7. doi: 10.1111/ijs.12317.

4. Mozaffarian D, Benjamin EJ, Go AS, Arnett DK, Blaha MJ, Cushman M, de Ferranti S, Després JP, Fullerton HJ, Howard VJ, Huffman MD, Judd SE, Kissela BM, Lackland DT, Lichtman JH, Lisabeth LD, Liu S, Mackey RH, Matchar DB, McGuire DK, Mohler ER 3rd, Moy CS, Muntner P, Mussolino ME, Nasir K, Neumar RW, Nichol G, Palaniappan L, Pandey DK, Reeves MJ, Rodriguez CJ, Sorlie PD, Stein J, Towfighi A, Turan TN, Virani SS, Willey JZ, Woo D, Yeh RW, Turner MB; American Heart Association Statistics Committee and Stroke Statistics Subcommittee. Heart disease and stroke statistics--2015 update: a report from the American HeartAssociation. Circulation. 2015 Jan 27;131(4):e29-322. doi: 10.1161/CIR.0000000000000152. Epub 2014 Dec 17. Erratum in: Circulation. 2015 Jun 16;131(24):e535. Erratum in: Circulation. 2016 Feb 23;133(8):e417.

5. Ovbiagele B, Goldstein LB, Higashida RT, Howard VJ, Johnston SC, Khavjou OA, Lackland DT, Lichtman JH, Mohl S, Sacco RL, Saver JL, Trogdon JG; American Heart Association Advocacy Coordinating Committee and Stroke Council. Forecasting the future of stroke in the United States: a policy statement from the American Heart Association and American Stroke Association. Stroke. 2013 Aug;44(8):236175. doi: 10.1161/STR.0b013e31829734f2. Epub 2013 May 22. Erratum in: Stroke. 2015 Jul;46(7):e179.

6. Langhorne P, Stott DJ, Robertson L, MacDonald J, Jones L, McAlpine C, Dick F, Taylor GS, Murray G. Medical complications after stroke: a multicenter study. Stroke. 2000 Jun;31(6):1223-9. doi: 10.1161/01.str.31.6.1223.

7. Ugur C, Gücüyener D, Uzuner N, Ozkan S, Ozdemir G. Characteristics of falling in patients with stroke. J Neurol Neurosurg Psychiatry. 2000 Nov;69(5):649-51. doi: 10.1136/ jnnp.69.5.649.

8. Teasell R, McRae M, Foley N, Bhardwaj A. The incidence and consequences of falls in stroke patients during inpatient rehabilitation: factors associated with high risk. Arch Phys Med Rehabil. 2002 Mar;83(3):329-33. doi: 10.1053/ apmr.2002.29623.

9. Blake AJ, Morgan K, Bendall MJ, Dallosso H, Ebrahim SB, Arie TH, Fentem PH, Bassey EJ. Falls by elderly people at home: prevalence and associated factors. Age Ageing. 1988 Nov;17(6):365-72. doi: 10.1093/ageing/17.6.365.

10. Aizen E, Shugaev I, Lenger R. Risk factors and characteristics of falls during inpatient rehabilitation of elderly patients. Arch Gerontol Geriatr. 2007 Jan-Feb;44(1):1-12. doi: 10.1016/j.archger.2006.01.005.

11. Ashburn A, Hyndman D, Pickering R, Yardley L, Harris S. Predicting people with stroke at risk of falls. Age Ageing. 2008 May;37(3):270-6. doi: 10.1093/ageing/afn066.

12. Berg WP, Alessio HM, Mills EM, Tong C. Circumstances and consequences of falls in independent community-dwelling older adults. Age Ageing. 1997 Jul;26(4):261-8. doi: 10.1093/ ageing/26.4.261.

13. Nilsagård Y, Denison E, Gunnarsson LG, Boström K. Factors perceived as being related to accidental falls by persons with multiple sclerosis. Disabil Rehabil. 2009;31(16):130110. doi: 10.1080/09638280802532639.

14. Hyndman D, Ashburn A. People with stroke living in the community: Attention deficits, balance, ADL ability and falls. Disabil Rehabil. 2003 Aug 5;25(15):817-22. doi: 10.1080/0963828031000122221.

15. Hyndman D, Ashburn A, Stack E. Fall events among people with stroke living in the community: circumstances of falls and characteristics of fallers. Arch Phys Med Rehabil. 2002 Feb;83(2):165-70. doi: 10.1053/apmr.2002.28030.

16. Schmid AA, Van Puymbroeck M, Altenburger PA, Miller KK, Combs SA, Page SJ. Balance is associated with quality of life in chronic stroke. Top Stroke Rehabil. 2013 JulAug;20(4):340-6. doi: 10.1310/tsr2004-340.

17. Tinetti ME. Clinical practice. Preventing falls in elderly persons. N Engl J Med. 2003 Jan 2;348(1):42-9. doi: 10.1056/ NEJMcp020719.

18. Hausdorff JM, Rios DA, Edelberg HK. Gait variability and fall risk in community-living older adults: a 1-year prospective study. Arch Phys Med Rehabil. 2001 Aug;82(8):1050-6. doi: 10.1053/apmr.2001.24893.

19. Forster A, Young J. Incidence and consequences of falls due to stroke: a systematic inquiry. BMJ. 1995 Jul 8;311(6997):83-6. doi: 10.1136/bmj.311.6997.83.

20. Nachreiner NM, Findorff MJ, Wyman JF, McCarthy TC. Circumstances and consequences of falls in communitydwelling older women. J Womens Health (Larchmt). 2007 Dec;16(10):1437-46. doi: 10.1089/jwh.2006.0245.

21. Phipps MS, Schmid AA, Kapoor JR, Peixoto AJ, Williams LS, Bravata DM. Orthostatic hypotension among outpatients with ischemic stroke. J Neurol Sci. 2012 Mar 15;314(1-2):625. doi: 10.1016/j.jns.2011.10.031.

22. Campbell AJ, Borrie MJ, Spears GF. Risk factors for falls in a community-based prospective study of people 70 years and older. J Gerontol. 1989 Jul;44(4):M112-7. doi: 10.1093/ geronj/44.4.m112.

23. Tinetti ME, Kumar C. The patient who falls: "It's always a trade-off”. JAMA. 2010 Jan 20;303(3):258-66. doi: 10.1001/ jama.2009.2024. PMID: 20085954;

24. Deandrea S, Lucenteforte E, Bravi F, Foschi R, La Vecchia C, Negri E. Risk factors for falls in communitydwelling older people: a systematic review and meta-analysis. Epidemiology. 2010 Sep;21(5):658-68. doi: 10.1097/ EDE.0b013e3181e89905.

25. Srikanth V, Beare R, Blizzard L, Phan T, Stapleton J, Chen J, Callisaya M, Martin K, Reutens D. Cerebral white matter lesions, gait, and the risk of incident falls: a prospective population-based study. Stroke. 2009 Jan;40(1):175-80. doi: 10.1161/STROKEAHA.108.524355.

26. Leveille SG, Jones RN, Kiely DK, Hausdorff JM, Shmerling RH, Guralnik JM, Kiel DP, Lipsitz LA, Bean JF. Chronic musculoskeletal pain and the occurrence of falls in an older population. JAMA. 2009 Nov 25;302(20):2214-21. doi: 10.1001/jama.2009.1738.

27. Mosnaim AD, Abiola R, Wolf ME, Perlmuter LC. Etiology and risk factors for developing orthostatic hypotension. Am J Ther. 2010 Jan-Feb;17(1):86-91. doi: 10.1097/ MJT.0b013e3181a2b1bb.

28. Ganz DA, Bao Y, Shekelle PG, Rubenstein LZ. Will my patient fall? JAMA. 2007 Jan 3;297(1):77-86. doi: 10.1001/ jama.297.1.77.

29. Wing JJ, Burke JF, Clarke PJ, Feng C, Skolarus LE. The role of the environment in falls among stroke survivors. Arch Gerontol Geriatr. 2017 Sep;72:1-5. doi: 10.1016/j. archger.2017.04.007. Epub 2017 May 1.

30. Jørgensen L, Engstad T, Jacobsen BK. Higher incidence of falls in long-term stroke survivors than in population controls: depressive symptoms predict falls after stroke. Stroke. 2002 Feb;33(2):542-7. doi: 10.1161/hs0202.102375.

31. Weerdesteyn V, de Niet M, van Duijnhoven HJ, Geurts AC. Falls in individuals with stroke. J Rehabil Res Dev. 
2008;45(8):1195-213.

32. Divani AA, Vazquez G, Barrett AM, Asadollahi M, Luft AR. Risk factors associated with injury attributable to falling among elderly population with history of stroke. Stroke. 2009 Oct;40(10):3286-92. doi: 10.1161/ STROKEAHA.109.559195.

33. Simpson LA, Miller WC, Eng JJ. Effect of stroke on fall rate, location and predictors: a prospective comparison of older adults with and without stroke. PLoS One. $2011 \mathrm{Apr}$ 29;6(4):e19431. doi: 10.1371/journal.pone.0019431.

34. Letts L, Moreland J, Richardson J, Coman L, Edwards M, Ginis KM, Wilkins S, Wishart L. The physical environment as a fall risk factor in older adults: Systematic review and meta-analysis of cross-sectional and cohort studies. Aust Occup Ther J. 2010 Feb;57(1):51-64. doi: 10.1111/j.14401630.2009.00787.x.

35. Li W, Keegan TH, Sternfeld B, Sidney S, Quesenberry CP Jr, Kelsey JL. Outdoor falls among middle-aged and older adults: a neglected public health problem. Am J Public Health. 2006 Jul;96(7):1192-200. doi: 10.2105/AJPH.2005.083055.

36. Guideline for the prevention of falls in older persons. American Geriatrics Society, British Geriatrics Society, and American Academy of Orthopaedic Surgeons Panel on Falls Prevention. J Am Geriatr Soc. 2001 May;49(5):664-72.

37. Nyman SR, Ballinger C, Phillips JE, Newton R. Characteristics of outdoor falls among older people: a qualitative study. BMC Geriatr. 2013 Nov 18;13:125. doi: 10.1186/1471-2318-13-125.

38. Chippendale T, Boltz M. The Neighborhood Environment: Perceived Fall Risk, Resources, and Strategies for Fall Prevention. Gerontologist. 2015 Aug;55(4):575-83. doi: 10.1093/geront/gnu019.

39. Albert SM, King J, Boudreau R, Prasad T, Lin CJ, Newman AB. Primary prevention of falls: effectiveness of a statewide program. Am J Public Health. 2014 May;104(5):e77-84. doi: 10.2105/AJPH.2013.301829.

40. Albert SM, Edelstein O, King J, Flatt J, Lin CJ, Boudreau
R, Newman AB. Assessing the quality of a non-randomized pragmatic trial for primary prevention of falls among older adults. Prev Sci. 2015 Jan;16(1):31-40. doi: 10.1007/s11121014-0466-2.

41. Lord SR, Menz HB, Sherrington C. Home environment risk factors for falls in older people and the efficacy of home modifications. Age Ageing. 2006 Sep;35 Suppl 2:ii55-ii59. doi: 10.1093/ageing/afl088.

42. Gillespie LD, Gillespie WJ, Robertson MC, Lamb SE, Cumming $\mathrm{RG}$, Rowe $\mathrm{BH}$. Interventions for preventing falls in elderly people. Cochrane Database Syst Rev. 2003;(4):CD000340. doi: 10.1002/14651858.CD000340.

43. Kalyani RR, Stein B, Valiyil R, Manno R, Maynard JW, Crews DC. Vitamin D treatment for the prevention of falls in older adults: systematic review and meta-analysis. J Am Geriatr Soc. 2010 Jul;58(7):1299-310. doi: 10.1111/j.15325415.2010.02949.x.

44. Bischoff-Ferrari HA, Dawson-Hughes B, Staehelin HB, Orav JE, Stuck AE, Theiler R, Wong JB, Egli A, Kiel DP, Henschkowski J. Fall prevention with supplemental and active forms of vitamin D: a meta-analysis of randomised controlled trials. BMJ. 2009 Oct 1;339:b3692. doi: 10.1136/bmj.b3692. 45. Haran MJ, Cameron ID, Ivers RQ, Simpson JM, Lee BB, Tanzer M, Porwal M, Kwan MM, Severino C, Lord SR. Effect on falls of providing single lens distance vision glasses to multifocal glasses wearers: VISIBLE randomised controlled trial. BMJ. 2010 May 25;340:c2265. doi: 10.1136/bmj.c2265. Erratum in: BMJ. 2016 May 27;353:i3041.

46. McKiernan FE. A simple gait-stabilizing device reduces outdoor falls and nonserious injurious falls in fall-prone older people during the winter. J Am Geriatr Soc. 2005 Jun;53(6):943-7. doi: 10.1111/j.1532-5415.2005.53302.x.

47. Kenny RA, Richardson DA, Steen N, Bexton RS, Shaw FE, Bond J. Carotid sinus syndrome: a modifiable risk factor for nonaccidental falls in older adults (SAFE PACE). J Am Coll Cardiol. 2001 Nov 1;38(5):1491-6. doi: 10.1016/s07351097(01)01537-6. 